\title{
Rancang Bangun Website Sekolah Untuk Peningkatan Kapasitas Sekolah Dasar Negeri Menjadi Sekolah Adiwiyata, Terakreditasi dan Role Model Di Balikpapan Tengah
}

\author{
Ihsan', Nur Yanti², Dwi Lesmideyarti ${ }^{3}$ \\ ${ }_{1,2,3}^{2,3}$ urusan Teknik Elektro, Politeknik Negeri Balikpapan,_Jl. Soekarno Hatta No.KM.8, \\ Batu Ampar, Kec. Balikpapan Utara, Kota Balikpapan, Kalimantan Timur 76129 Indonesia \\ email:ihsan@poltekba.ac.id
}

\begin{abstract}
Abstrak
Dunia pendidikan baik dari tingkat sekolah dasar hingga perguruan tinggi dituntut dapat beradaptasi dengan kemajuan ipteks yang berkembang begitu pesat, terutama dibidang informasi. Serta kondisi pandemi Covid19 saat ini menuntut setiap institusi membantu menekan angka penyebarannya. Salah satu lini masyarakat yang terdampak Covid19 ini adalah sekolah, terutama sekolah dasar yang belum memiliki fasilitas website sekolah sebagai media informasi ke masyarakat. Dalam kegiatan pengabdian kepada masyarakat ini tim pelaksana merancang bangun website sekolah SDN 020 Balikpapan Tengah sebagai mitra. Permasalahan yang dihadapi oleh mitra adalah letak sekolah yang kurang strategis di wilayah Balikpapan Tengah, tidak memiliki media yang infomatif untuk berbagai aspek kepentingan, adanya kebijakan PPDB online dari Dinas Pendidikan untuk menekan penyebaran Covid19, Untuk mengatasi berbagai masalah ini, SDN 020 Balikpapan Tengah harus memiliki website. Manfaatnya kegiatan PPDB online dapat dilaksanakan sehingga wali murid tidak perlu ke sekolah saat pendaftaran, dapat memenuhi persyaratan sebagai sekolah Adiwiyata, dan dapat memudahkan pencapaian akreditasi sekolah. Adapun metode pelaksanaan kegiatan pengabdian oleh tim terdiri dari membangun komunikasi dengan mitra, merancang website sekolah, memberikan pelatihan penggunaan website berupa pengisian konten dan pengelolaan database, implementasi website di sekolah, sosialisais website sekolah ke lingkungan masyarakat, perawatan dan perbaikan website pasca implementasi. Rangkaian kegiatan pengabdian kepada masyarakat ini direncanakan maksimal 8 bulan. Kegiatan pengabdian berlangsung dengan sukses dan dapat membantu operator sekolah dalam pengolahan data dan menyeleksi calon peserta didik dengan mudah dan cepat
\end{abstract}

Kata kunci: PPDB; SDN 020; Website

\begin{abstract}
The world of education, from elementary school to university levels, is required to be able to adapt to the progress of science and technology that is growing so rapidly, especially in the field of information. And the current state of the Covid-19 pandemic requires every institution to help reduce the number of its spread. One of the lines of society affected by COVID-19 is schools, especially elementary schools that do not yet have school website facilities as a medium of information to the public. In this community service activity, the implementing team designed the website for the SDN 020 Central Balikpapan school as a partner. The problems faced by partners are the location of schools that are not strategically located in the Central Balikpapan area, not having informative media for various aspects of interest, the existence of an online PPDB policy from the Education Office to suppress the spread of Covid19, To overcome these problems, SDN 020 Central Balikpapan must have websites. The benefits of online PPDB activities can be carried out so that parents do not need to go to school during registration, can meet the requirements as an Adiwiyata school, and can facilitate the achievement of school accreditation. The method of implementing community service activities by the team consists of building communication with partners, designing school websites, providing training on the use of websites in the form of filling out content and managing databases, implementing websites in schools, socializing school websites to the community,
\end{abstract}


maintaining and repairing websites after implementation. This series of community service activities is planned for a maximum of 8 months. The service activity took place successfully and could help school operators in data processing and selecting prospective students easily and quickly

Keywords: PPDB, SDN 020, Website

(C) 2021 Ihsan, Nur Yanti, Dwi Lesmideyarti Under the license CC BY-SA 4.0

Correspondence author: Ihsan, ihsan@poltekba.ac.id, Balikpapan, and Indonesia

\section{PENDAHULUAN}

Perkembangan teknologi informasi sekarang ini khususnya teknologi internet banyak sekali potensi sumber daya yang dapat dimanfaatkan. Pentingnya website bagi sekolah tidak hanya sekedar fasilitas untuk dunia pendidikan dan mendapatkan informasi terbaru terkait pendidikan, namun juga bisa memberi kesan yang baik dan profesionalisme untuk sekolah. Website sekolah saat ini tengah menjadi trend di dunia pendidikan dan memperoleh perhatian, tanggapan yang sangat baik dari berbagai pihak baik dari tenaga kependidikan, siswa dan masyarakat. Website dapat dijadikan sebagai media pembelajaran online (e-learning), hingga promosi. Website sekolah juga memberikan penilaian tersendiri untuk berbagai kepentingan seperti akreditasi sekolah, Penerimaan Penerimaan Peserta Didik Baru (PPDB) online serta untuk memperoleh penghargaan Adiwiyata.

Meskipun SDN 020 telah memiliki fasilitas umum berupa jaringan internet dalam melaksanakan pendidikan, namun belum memiliki website sekolah. Keberadaan sekolah juga hanya diketahui oleh penduduk sekitar yang bertempat tinggal dekat dengan lokasi sekolah, sehingga hal ini mengakibatkan SDN 020 Balikpapan Tengah tidak menjadi pilihan utama bagi masyarakat sekitar. Perkembangan sekolah menjadi lambat. Di lokasi yang sama juga terdapat Sekolah Dasar Negeri yang lain, dimana tata letak sekolah tersebut lebih strategis yaitu berada dipinggir jalan besar. Sedangkan jalan meuju ke SDN 020 melalui jalan kecil dalam lingkungan rumah padat penduduk. Kegiatan-kegiatan guru dan siswa serta prestasi yang menunjang peningkatan mutu pendidikan tidak terpublikasikan dikarenakan tidak memiliki media publikasi seperti website sekolah. Fasilitas internet hanya digunakan sebatas untuk melakukan 
pembelajaran daring untuk para guru selama pandemi Covid19, kegiatan administrasi menggunakan email. Berdasarkan analisis situasi diatas, mitra SDN 020 Balikpapan Tengah, dalam melakukan tugas dan fungsi sebagai penyelenggara pendidikan pada tingkat dasar menghadapi beberapa masalah dalam peningkatan kapasitas sumber daya baik berupa sarana prasarana maupun sumber daya manusia. Berdasarkan hasil diskusi tim pelaksana Politeknik Negeri Balikpapan dengan mitra SDN 020 Balikpapan Tengah, teridentifikasi beberapa masalah yang dihadapi oleh mitra, antara lain Permasalahan terkait kredibilitas sekolah artinya belum menjadi pilihan utama untuk memperoleh pendidikan dasar bagi sebagian besar warga yang berdomisili di wilayah keberadaan sekolah. Sehingga sekolah perlu meningkatkan kepercayaan masyarakat terhadap sekolah. Yang kedua Tidak memiliki media yang informatif untuk berbagai aspek kepentingan. Dan yang ketiga adalah adanya kebijakan PPDB online dari Dinas Pendidikan Kota Balikpapan, serta kurangnya Sumber Daya Manusia (SDM) yang tanggap Iptek. Dengan adanya kegiatan pengabdian ini diharapkan dapat meningkatkan kapasitas Sekolah Dasar Negeri 020 Balikpapan Tengah menjadi sekolah adiwiyata, terakreditasi dan role model di balikpapan tengah.

\section{METODE PELAKSANAAN}

Kegiatan ini dilaksanakan dengan menggunakan pendekatan metode waterfall. Alur pelaksanaan kegiatan ditunjukkan pada gambar 1.

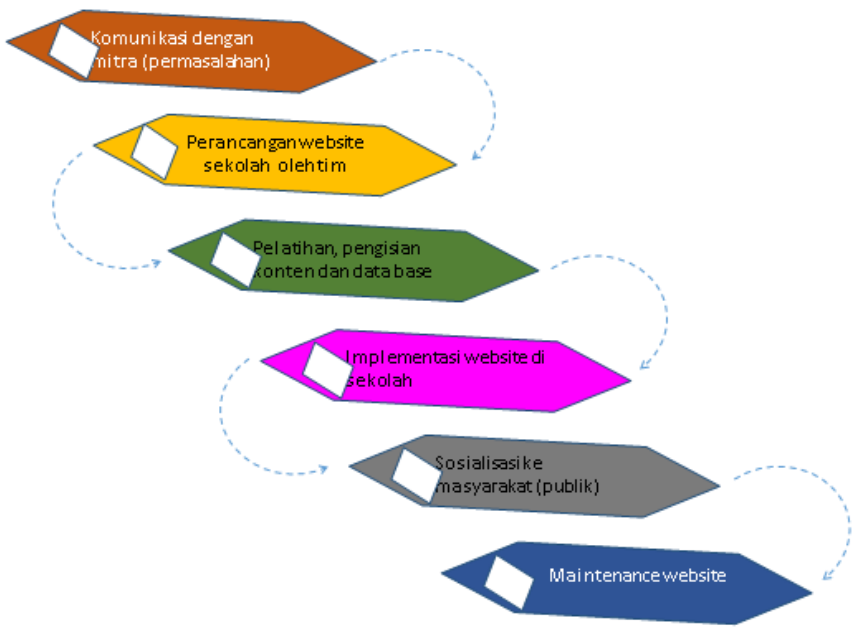

Gambar 1. Metode Pelaksanaan Waterfall 
Urian dari tahap metode pelaksanaan waterfall sebagai berikut adalah Langkah pertama Requirements Analysis tahap ini merupakan tahap awal, pada tahap ini perancangan website sekolah diperlukan suatu komunikasi yang bertujuan untuk memahami permasalahan atau kebutuhan mitra. Informasi diperoleh dari survey ke lokasi dan berdiskusi dengan mitra. Tujuannya agar website yang dirancang oleh tim pelaksana sesuai dengan kebutuhan mitra dan dapat mengatasi permasalahan di lingkungan mitra. Langkah kedua System Design Pada proses desain ini, dilakukan perancangan website oleh tim pelaksana pengabdian. Proses ini berfokus pada struktur data, arsitektur website, representasi interface, dan detail pemrograman atau algoritma desain website. Perancangan struktur websiteatau fitur-fitur yang berada dalam website mengadopsi kepentingan sekolah dan masyarakat. Langkah ketiga Pelatihan, pengisian konten dan pengolahan data base Pada tahap ini operator website sekolah memiliki peran sangat penting, yaitu mengelola website tersebut, sehingga operator harus memiliki kecakapan dalam mengelola database, pengisian dan perbaharuan isi konten, sehingga perlu dibekali dengan keterampilan melalui pelatihan pengisian konten website dan pengelolaan database sekolah. Diharapkan website sekolah akan terus aktif dan berisi informasi yang up to datesebagai sarana sumber informasi dari pihak sekolah kepada masyarakat. Langkah keempat Implementasi Website Di Sekolah Setelah operator mengisi konten dengan informasi yang penting dan menarik, website diuji coba dengan mengimplementasikan website di kalangan internal sekolah. Setelah website berjalan normal, tidak terdapat kendala, serta fitur-fitur yang terdapat di dalam website telah sesuai dengan kebutuhan sekolah untuk pelaksanaan kegiatan PPDB online, memenuhi prasyaratan sekolah Adiwiyata dan akreditasi. Diharapkan informasi yang ditampilkan di website merupakan informasi yang terbaru, sehingga website sekolah ini memiliki daya tarik tersendiri bagi siswa, wali murid serta masyarakat lingkungan sekitar. Langkah kelima Sosialisasi ke Masyarakat (Publik) Setelah website ready to use, maka pihak sekolah melakukan sosialisasi 
ke masyarakat luas, khususnya masyarakat sekitar yang berdomisili di wilayah SDN 020 berada. Tujuan dari sosialisasi ini untuk menginformasikan kepada masyarakat terkait ketersediaan website sekolah, manfaat, serta tata cara mengakses informasi dari websiteterkait profil sekolah, kegiatan KBM, prestasi siswa dan informasi penting lainnya. Hal ini sebagai upaya pihak sekolah dalam menunjukkan eksistensinya, meningkatkan kepercayaan masyarakat terhadap institusi SDN 020. Dan terpenting adalah membantu masyarakat dalam melakukan pendaftaran PPDB online, untuk mencegah angka penyebaran Covid19 semakin meluas.

Saat sosialisasi website sekolah ke masyarakat, tim pelaksana pengabdian mendampingi pihak sekolah dalam kegiatan tersebut, sehingga jika terjadi kendala teknis dapat segera diatasi atau ditindaklanjuti. Langkah keenam Maintenance Website Kegiatan maintenance website ini dilakukan setelah website sekolah dioperasikan secara menerus. Sehingga perlu dilakukan maintenace seperti pengecekan perangkat lunak, isi konten dan jaringan internet. Maintenance ini sebagai monitoring dan evaluasi bagi tim pelaksana pengabdian terkait dampak ketersediaan website terhadap peningkatan mutu layanan (kapasitas) sekolah, peningkatan belajar serta kemudahan akses bagi siswa, wali murid dan masyarakat. Maintenance adalah hal yang mestinya rutin dan penting dilakukan oleh tim pelaksana untuk keberlangsungan dan pengembangan website sekolah dari sistem ataupun perangkat lunak lainnya. Jika terdapat masalah atau error pada software dapat segera ditindaklanjuti.

\section{HASIL DAN PEMBAHASAN}

Hasil

Kegiatan Pengabdian Kepada Masyarakat (PkM) di SDN 020 Balikpapan Tengah yang beralamat di JI. DR. Sutomo No.23, Sumber Rejo, Kec. Balikpapan Tengah, Kota Balikpapan, Kalimantan Timur sebagaimana tertera pada tabel 1 berikut ini : 
Tabel 1 Road Map Kegiatan Pengabdian Kepada Masyarakat di SDN 020

Balikpapan Tengah

\begin{tabular}{|c|c|c|c|}
\hline No. & $\begin{array}{c}\text { Waktu } \\
\text { Kegiatan }\end{array}$ & Uraian Kegiatan & Hasil \\
\hline 1 & $\begin{array}{l}27 \text { Februari } \\
2021\end{array}$ & $\begin{array}{l}\text { Berkomunikasi dengan pihak mitra } \\
\text { dengan tujuan untuk memahami } \\
\text { permasalahan atau kebutuhan } \\
\text { mitra. Informasi diperoleh dari } \\
\text { survey ke lokasi dan berdiskusi } \\
\text { dengan mitra. }\end{array}$ & $\begin{array}{l}\text { Pihak mitra } \\
\text { membutuhkan } \\
\text { Website }\end{array}$ \\
\hline 2 & April 2021 & $\begin{array}{l}\text { Perancangan website oleh tim } \\
\text { pelaksana pengabdian. Proses ini } \\
\text { berfokus pada struktur data, } \\
\text { arsitektur website, representasi } \\
\text { interface, dan detail pemrograman } \\
\text { atau algoritma desain website. }\end{array}$ & $\begin{array}{l}\text { Website telah } \\
\text { selesai dibuat } \\
\text { sesuai dengan } \\
\text { permintaan mitra }\end{array}$ \\
\hline 3 & $\begin{array}{l}08 \mathrm{Mei} \\
2021\end{array}$ & $\begin{array}{l}\text { Pelatihan, pengisian konten dan } \\
\text { pengolahan database }\end{array}$ & $\begin{array}{l}\text { Operator } \\
\text { sekolah telah } \\
\text { mampu meng- } \\
\text { upload } \\
\text { informasi ke web }\end{array}$ \\
\hline 4 & $\begin{array}{l}20 \mathrm{Mei} \\
2021\end{array}$ & $\begin{array}{l}\text { Implementasi Website Di Sekolah, } \\
\text { website diuji coba dengan } \\
\text { mengimplementasikan website di } \\
\text { kalangan internal sekolah. Setelah } \\
\text { website berjalan normal, tidak } \\
\text { terdapat kendala, serta fitur-fitur } \\
\text { yang terdapat di dalam website }\end{array}$ & $\begin{array}{l}\text { Website telah } \\
\text { sesuai dengan } \\
\text { kebutuhan } \\
\text { sekolah untuk } \\
\text { pelaksanaan } \\
\text { kegiatan PPDB } \\
\text { online }\end{array}$ \\
\hline 5 & $\begin{array}{l}07 \text { Juni } \\
2021\end{array}$ & $\begin{array}{l}\text { Sosialisasi ke Masyarakat (publik), } \\
\text { pihak sekolah didampingi tim PkM } \\
\text { Poltekba melakukan sosialisasi ke } \\
\text { masyarakat luas, khususnya } \\
\text { masyarakat sekitar yang berdomisili } \\
\text { di wilayah SDN } 020 \text {. }\end{array}$ & $\begin{array}{l}\text { Website sudah } \\
\text { bisa digunakan } \\
\text { untuk PPDB } \\
\text { online oleh } \\
\text { masyarakat } \\
\text { sekitar SDN } 020\end{array}$ \\
\hline
\end{tabular}




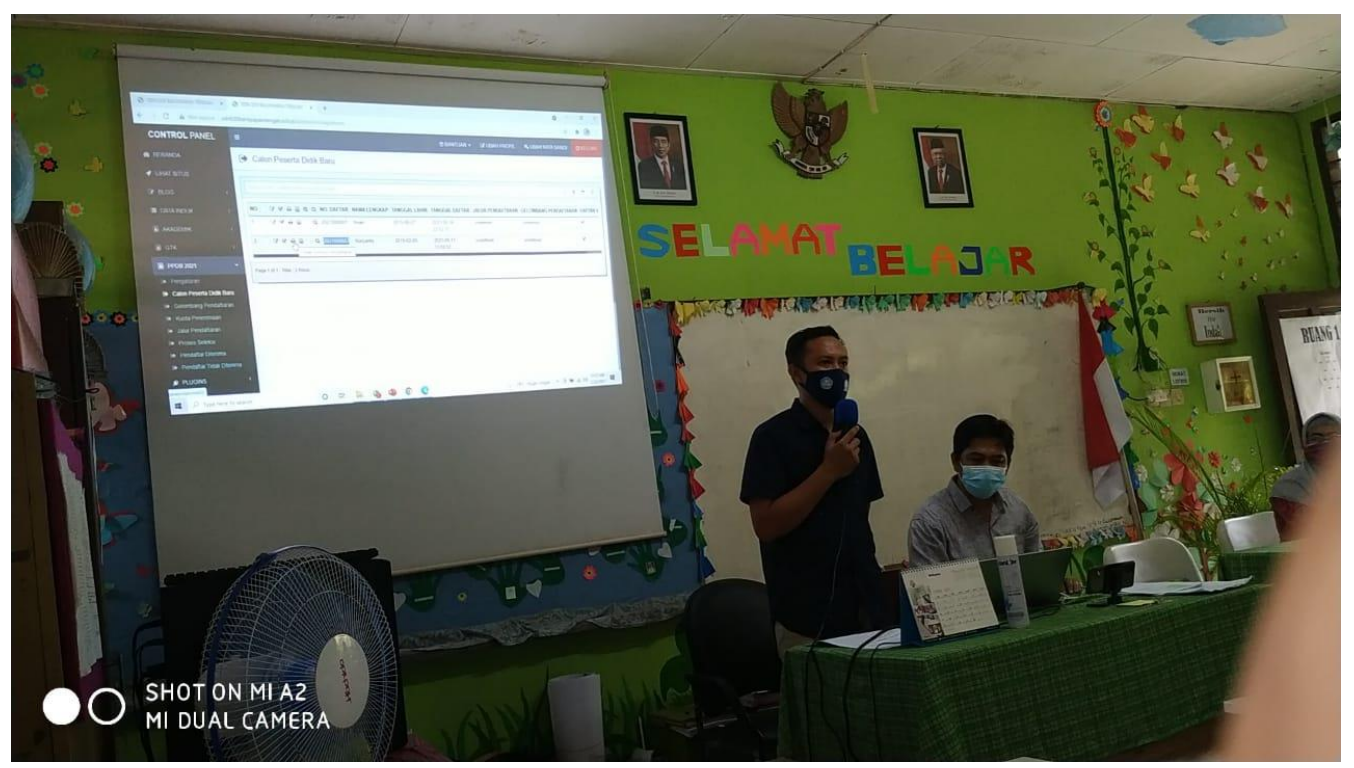

Gambar 2. Kegiatan sosialisasi Website kepada masyarakat sekitar oleh Tim PkM Poltekba

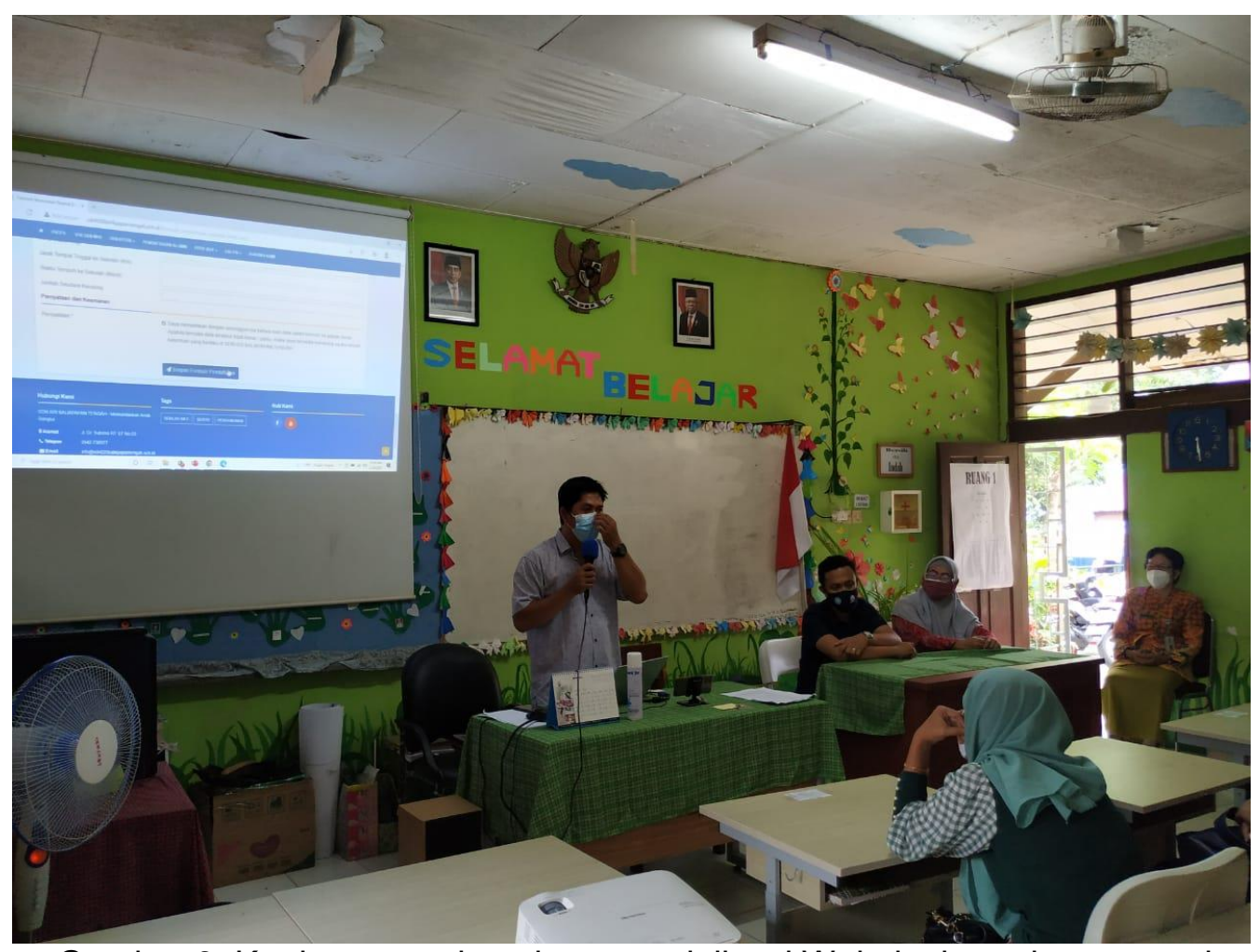

Gambar 3. Kegiatan pendampingan sosialisasi Website kepada masyarakat sekitar oleh operator sekolah 


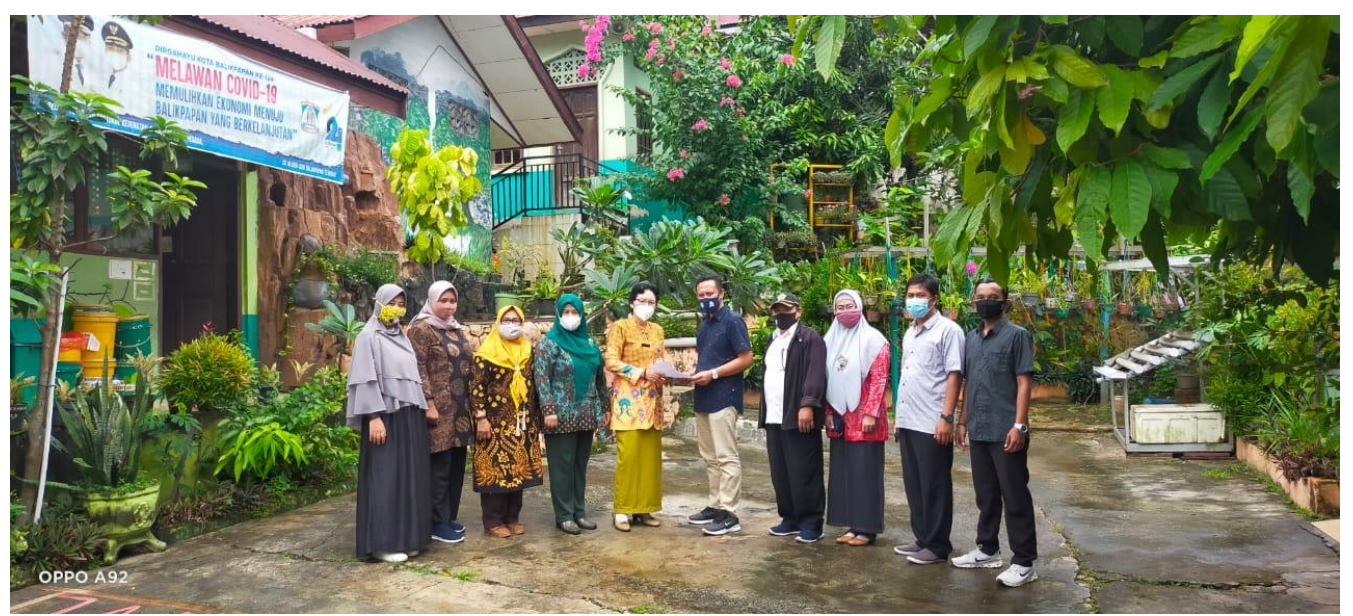

Gambar 4. Serah Terima Produk PkM (Website Sekolah) antara Kepala SDN 020 dengan Tim Poltekba

\section{Pembahasan}

Pembuatan rancang bangun website PPDB online untuk SDN 020 Balikpapan Tengah ini sangat membantu dan memudahkan operator sekolah dalam mengelola data calon siswa/i baru, memberikan informasi penting, dan bisa mengelola data alumni dan juga memudahkan pihak masyarakat dalam proses pendaftaran sekolah anak-anak mereka. Kegiatan pendampingan dan sosialisasi kepada masyarakat ini dilaksanakan selama setengah hari yang dilaksanakan di salah satu ruangan kelas yang dihadiri sekitar 50 orang tua/wali murid. Rangkaian kegiatan ini berlangsung dengan aman, lancar, dan sukses atas dukungan seluruh lapisan masyarakat, serta pihak sekolah dan pihak kelurahan Sumber Rejo Balikpapan Tengah yang selalu membantu baik sarana maupun prasarana untuk memudahkan kegiatan.

Respon pihak sekolah dan masyarakat sekitar saat sosialisasi sangat baik dan atusiasme yang sangat baik. Bapak Lurah Sumber Rejo sangat mengapresiasi pembuatan sistem pendaftaran dan sharing informasi bisa dilakukan dengan online. Tidak hanya itu, adanya sistem ini dinilai akan sangat bermanfaat untuk mengatasi masalah-masalah dalam hal pendataan siswa. Sistem pada website ini juga mendukung pembuatan surat menyurat secara online misalnya menyampaikan kritik 
dan saran untuk kemajuan sekolah, sehingga pihak sekolah merasa terbantu dengan adanya sistem ini.

Pada saat sosialisasi juga terdapat beberapa saran dan perbaikan mengenai sistem yang diimplementasikan, seperti penambahan server yang lebih besar serta perlu meningkatkan kecepatan server dan pengembangan sistem agar terintegrasi dengan Dinas Pendidikan Kota Balikpapan.

Dalam pelaksananannya terdapat kendala yaitu beberapa masyarakat tidak dapat kami sosialisasikan semua dikarenakan sedang masa pandemi covid 19 sehingga tidak dapat menghadiri pertemuan tersebut. Akan tetapi hal tersebut dapat diatasi dikarenakan bantuan dari lurah, komite serta para dewan guru yang juga membantu dalam menyampaikan kepada masyarakat sekitar SDN 020 Balikpapan Tengah. Kendala yang kedua dialami saat pelaksanaan kegiatan sosialisasi tersebut yaitu kurangnya pemahaman masyarakat dalam memahami isi materi yang dipaparkan akan tetapi dengan adanya pendampingan dan penjelasan dari tim PkM dosen dari Politeknik Negeri Balikpapan maka permasalahan tersebut dapat teratasi dengan mudah.

\section{KESIMPULAN}

Kesimpulan dari pelaksanaan pengabdian pembuatan Website Penerimaan Peserta Didik Baru (PPDB) online SDN 020 Balikpapan Tengah adalah Website yang dibangun sudah sesuai dengan requirement yang ada SDN 020 Balikpapan Tengah, website dapat memudahkan orang tua / wali calon peserta didik baru untuk mendaftar di SDN 020 Balikpapan Tengah khususnya di masa pandemi seperti ini, dan website dapat membantu dalam pengolahan data dan menyeleksi calon peserta didik dengan mudah dan cepat, untuk pengembangan selanjutnya

Website ini perlu ditambahkan fungsi SMS Gateway untuk memberitahu kepada peserta didik yang diterima di SDN 020 Balikpapan Tengah, dan website ini juga dapat dikembangkan ke arah Blended Learning untuk memudahkan pembelajaran secara online/ daring. 


\section{UCAPAN TERIMA KASIH}

Terima kasih kepada P3M Politeknik Negeri Balikpapan untuk pendanaan yang telah diberikan sehingga kegiatan pengabdian pada SDN 020 Balikpapan Tengah di Kota Balikpapan berjalan dengan lancar.

\section{REFERENCES}

Aryanto, A.,Riasti, B,K,.2012. Pembuatan Sistem Informasi Perpustakaan Smp Muhammadiyah 7 Surakarta. Jurnal Speed Web - Volume 2 Nomor2 - 2012 ISSN : 977 2088015. Hal 1-8.

Christian, A., Hesinto,S., \& Agustina. 2018. Rancang Bangun Website Sekolah Dengan Menggunakan Framework Bootstrap. Jurnal SISFOKOM, Volume 07, Nomor 01, Maret 2018.

Hendrianto, Dani Eko. 2014. Pembuatan Sistem Informasi Perpustakaan Berbasis Website Pada Sekolah Menegah Pertama Negeri 1 Donorojo Kabupaten Pacitan. Jurnal Indonesian Journal on Networking and Security - Volume 3 No 4 - 2014 - ijns.org.

Irawan, Y., Susanti, N., \& Triyanto, A., W. 2016. Analisis Dan Perancangan Sistem Informasi Sekolah Berbasis Website Untuk Penyampaian Informasi Sekolah Dan Media Promosi Kepada Masyarakat. Jurnal Simetris. 07 (01), ISSN: 2252-4983.

Nugraha, Roni Sulistya. 2016. Sistem Informasi Sekolah Di Surakarta Berbasis Website. Jurnal Electronic Theses and Dissertations.

Riyadi, Retnadi, \& Supriatna. 2012. Perancangan Sistem Informasi Berbasis Website Subsistem Guru Di Sekolah Pesantren Persatuan Islam 99 Rancabango. Jurnal Algoritma Sekolah Tinggi Teknologi Garut. 09 (40), ISSN: 2302-7339. 